\title{
Utilization of Cotton Stalks-Biomass Waste in the Production of Carbon Adsorbents by KOH Activation for Removal of Dye-Contaminated Water
}

\author{
Nady A. Fathy ${ }^{\wedge, 1}$, Badie S Girgis ${ }^{1}$, Lila B. Khalil ${ }^{1}$ and Joseph Y. Farah² \\ ${ }^{1}$ Surface chemistry and Catalysis Laboratory, National Research Centre, 12622 El-Dokki, Giza, Egypt \\ ${ }^{2}$ Chemical Engineering Department, National Research Centre, 12622 El-Dokki, Giza, Egypt \\ ^e-mail:dr.nady2010@hotmail.com \\ (Received August 2, 2010; Accepted September 14, 2010)
}

\begin{abstract}
Four activated carbons were produced by two-stage process as followings; semi-carbonization of indigenous biomass waste, i.e. cotton stalks, followed by chemical activation with $\mathrm{KOH}$ under various activation temperatures and chemical ratios of $\mathrm{KOH}$ to semi-carbonized cotton stalks (CCS). The surface area, total pore volume and average pore diameter were evaluated by $\mathrm{N}_{2-}$ adsorption at $77 \mathrm{~K}$. The surface morphology and oxygen functional groups were determined by SEM and FTIR, respectively. Batch equilibrium and kinetic studies were carried out by using a basic dye, methylene blue as a probe molecule to evaluate the adsorption capacity and mechanism over the produced carbons. The obtained activated carbon (CCS-1K800) exhibited highly microporous structure with high surface area of $950 \mathrm{~m}^{2} / \mathrm{g}$, total pore volume of $0.423 \mathrm{~cm}^{3} / \mathrm{g}$ and average pore diameter of $17.8 \AA$. The isotherm data fitted well to the Langmuir isotherm with monolayer adsorption capacity of $222 \mathrm{mg} / \mathrm{g}$ for CCS-1K800. The kinetic data obtained at different concentrations were analyzed using a pseudo-first-order, pseudo-second-order and intraparticle diffusion equations. The pseudo-second-order model fitted better for kinetic removal of MB dye. The results indicate that such laboratory carbons could be employed as low cost alternative to commercial carbons in wastewater treatment.
\end{abstract}

Key words : Activated carbons, Porosity, Batch adsorption, Kinetic models, Methylene blue

\section{Introduction}

Among the different pollutants of the aquatic ecosystem, dyes are a large and important group of synthetic organic compounds (SOC). They are widely used in diverse industries such as textiles, paper, rubbers, plastics, foodstuffs, cosmetics, etc., to color their products. These dyes are invariably left in the industrial wastes and consequently discharged mostly in surface water resources. Dyes even in low concentrations are visually detected and meanwhile affect the aquatic life and food web. These colored compounds are not only asthetically displeasing but also inhibiting sunlight into the water streams and thus reduces the photosynthetic reactions [1]. It has been estimated that about 450,000 of dyestuffs produced in the world are discharged in textile wastewater [2]. The presence of organic dyes in water is harmful to human beings and aquatic life, thereof, the removal of color from wastewater becomes environmentally important. Amongst the conventional and physico-chemical methods used for the removal of dyes, activated carbon adsorption proved to be one of the most efficient and economic processes to remove them from wastewater [1,3-9]. Moreover, the adsorption of dyes onto active carbon depend surface charge on the carbon in the presence water. Activated carbons demonstrate a high capacity for both acid and basic dyes. The effects of various experimental parameters of dye adsorption are initial $\mathrm{pH}$, dye concentration, sorbent dosage, ion strength, and residence time. The inexpensive and readily available adsorbent provides an attractive alternative material for adsorption process. Despite its prolific use in water and wastewater industries, commercial activated carbon (CAC) still remains an expensive material. This has led to a research for low-cost materials as alternative adsorbent materials [9].

Another major problem facing rural villages in industrial developing countries are biomass, sewage and municipal solid waste. In Egypt the estimated amount of agricultural wastes ranges from 22 26 million dry tonnes/year. Five crops represent the highest amount of biomass wastes, these are: rice, corn, wheat/barely, cotton and sugar cane. The accumulation of these wastes causes many health problems and damage to the environment, e.g. the black clouds result from burning of biomass wastes in the field. One of the main wastes in Egypt is cotton stalks where its estimated amount of production is $1.6 \sim 3$ million tonnes annually [10].

A potentially profitable alternative method for cotton stalks reuse is the production of highly efficient adsorbents known as activated carbons [11-13]. It is well-known that carbon adsorbents 
have attracted special attention since many decades ago, because of their well-developed porous structure, large surface area and good mechanical properties $[14,15]$. Thus, activated carbon adsorbents introduce many applications on both the technical and laboratory scales. For example, they are used for; purification of sugar syrups, oil decolorization and for the improvement of taste and other properties of alcoholic beverages, as well as the purification of wastewaters and in chemical industries [14,15]. In general, activated carbon can be prepared from a large number of natural-rich in carbon materials, namely carbonaceous materials. The most commonly used raw materials in commercial practice are peat, lignite, wood and agricultural by-products (biomass). It has been found that activated carbons obtained from agricultural by-products can be favorably compared with other activated carbons used in industry with respect to their adsorptive properties [11]. Therefore, production of activated carbons from biomass serves dual purposes by converting unwanted surplus agricultural by-products to value-added and an efficient adsorbent for wastewater treatment and reduction of environmental and health hazards associated with the open burning of biomass wastes [3,13]. Examples of investigations utilizing agricultural biomass sources for activated carbon preparation in the recent two decades include: almond shells and peach stones [16]; olive-seed waste [17,18]; apricot stones [19]; sugarcane bagasse [20]; date pits [21]; nutshells and fruit stones [22]; and corn cobs or maize stalks [23-25].

Two schemes are employed for the production of activated carbons, the first being physical (i.e. thermal) activation of the preliminary-obtained char by an oxidizing gas (such as carbon dioxide, steam, air or mixture of gases). The second method, chemical activation, involves impregnation of carbonaceous precursor with a chemical agent that suppresses volatile components. Such chemical agents are $\mathrm{ZnCl}_{2}, \mathrm{H}_{3} \mathrm{PO}_{4}, \mathrm{KOH}$, $\mathrm{NaOH}$, etc, that promote the formation of cross-links, resulting in the generation of rigid matrix that hinders surface contraction upon pyrolysis process [23-27]. The advantages of chemical activation include low activation temperature, reduced activation time, high surface area, high yield and an important reduction of the mineral content [28]. The porous texture of the activated carbons depends on both the activation process and the nature of the precursor. The impact factors affect on the final textural properties of activated carbons prepared by chemical activation are as follows: activating agent, activating agent/C ratio, heating rate, activation temperature and soak time [29]. Accordingly, one of the effective variables on the porosity of the final carbon in chemical activation process is the activation temperature. However, it has been reported recently that activated carbons with high surface area can be developed by $\mathrm{KOH}$ activation of pre-carbonized cellulosic biomasses which are mostly of lower hardness (softer) and density than wood or fruit stone precursor such as corn cobs, rice straw, rice husk and cotton stalks $[24,30]$. This preparation method may be a mixed process of physical and chemical routes, and denoted as a two stage process.

Previous studies demonstrated the promise of producing an effective adsorbent either by $\mathrm{H}_{3} \mathrm{PO}_{4}$ activation of cotton stalks $[12,13]$ or $\mathrm{KOH}$ activation in one-stage [12]. However, very few researches have been reported to investigate the feasibility for production of activated carbons by semicarbonization followed by chemical activation of cotton stalks. Therefore, the objectives of this study were to investigate: (i) the feasibility of production of activated carbon by $\mathrm{KOH}$ activation of semi-carbonized cotton stalks (CCS) under different activation temperatures and chemical ratios of $\mathrm{KOH} / \mathrm{CCS}$ as $1: 1$ (at 700,750 and $800^{\circ} \mathrm{C}$ ) and $4: 1$ at $800^{\circ} \mathrm{C}$; (ii) the kinetics and mechanism of adsorption of methylene blue (MB) as probe molecules for technical and laboratory purposes [31] to find out the possibility of using these carbonaceous materials as low-cost adsorbents as well as iodine number detection. For this purpose, three simplified kinetic models (pseudo-first-order, pseudo-second-order and intraparticle diffusion) as well as two commonly isotherms in batch equilibrium (Langmuir and Freundlich isotherms) were performed to elucidate the adsorption mechanism.

\section{Experimental}

\subsection{Sample preparation}

A novel route of carbonization, a semi-carbonization was applied for producing a semi-carbonized cotton stalks [32]. Crushed cotton stalks were dried at $100^{\circ} \mathrm{C}$ overnight after washing with boiling water. Then, the dried cotton stalks were semi-carbonized at $200^{\circ} \mathrm{C}$ for $30 \mathrm{~min}$, then followed by raising the temperature up to $400^{\circ} \mathrm{C}$ and kept for another 30 min under its own atmosphere.

After the semi-carbonization step, the cooled-semi-carbonized cotton stalks (CCS) was mixed with $\mathrm{KOH}$ pellets, dissolved in small amount of water in a Pyrex dish with the prescribed $\mathrm{KOH} / \mathrm{CCS}$ ratio. The mixture was stirred vigorously for $1 \mathrm{~h}$ and placed in a stainless steel reactor. The activation temperature program was carried out by raising the temperature with heating rate at $10^{\circ} \mathrm{C} / \mathrm{min}$ until the desired activation temperature and kept for $30 \mathrm{~min}$ in a self-generated atmosphere. The activated mass was cooled to room temperature and washed sequentially with $1 \mathrm{~N} \mathrm{HCl}$ solution, followed by washing with boiling water, until $\mathrm{pH} \mathrm{6-7.} \mathrm{The} \mathrm{notation} \mathrm{of}$ the obtained samples and preparation conditions, in addition to carbon yield and ash content, are listed in Table 1.

\subsection{Determination of physico-chemical properties}

The textural parameters, such as the BET-surface area $\left(\mathrm{S}_{\mathrm{BET}}\right)$, total pore volume $\left(\mathrm{V}_{\mathrm{p}}\right)$ and average pore diameter $\left(R_{p}\right)$ were evaluated from BET-equation, using Quantachrome 
Table 1. Preparation Conditions of the Derived Samples from Semi-carbonized Cotton Stalks

\begin{tabular}{cccccc}
\hline \multirow{2}{*}{ Sample Notation } & \multicolumn{5}{c}{ Conditions of preparation } \\
\cline { 2 - 6 } & $\begin{array}{c}\mathrm{KOH} / \mathrm{CCS} \\
(\mathrm{w} / \mathrm{w})\end{array}$ & $\begin{array}{c}\text { Activation } \\
\text { temperature }\left({ }^{\circ} \mathrm{C}\right)\end{array}$ & $\begin{array}{c}\text { Activation time } \\
(\mathrm{min})\end{array}$ & $\begin{array}{c}\text { Yield } \\
(\%)\end{array}$ & $\begin{array}{c}\text { Ash } \\
(\%)\end{array}$ \\
\hline CCS-1K700 & $1: 1$ & 700 & 30 & 24.5 & 2.81 \\
CCS-1K750 & $1: 1$ & 750 & 30 & 23.8 & 3.02 \\
CCS-1K800 & $1: 1$ & 800 & 30 & 23 & 3.11 \\
CCS-4K800 & $4: 1$ & 800 & 30 & 12 & 3.22 \\
\hline
\end{tabular}

Table 2. Textural Properties of the Obtained Activated Carbons and Their Corresponding Iodine Number

\begin{tabular}{cccccccccc}
\hline $\begin{array}{c}\text { Sample } \\
\text { Notation }\end{array}$ & $\begin{array}{c}\mathrm{I}_{2} \\
\text { number } \\
(\mathrm{mg} / \mathrm{g})\end{array}$ & $\begin{array}{c}\mathrm{I}_{2} \\
\text { Coverage } \\
\mathrm{S}_{\mathrm{I}}\left(\mathrm{m}^{2} / \mathrm{g}\right)\end{array}$ & $\begin{array}{c}\mathrm{S}_{\mathrm{BET}} \\
\left(\mathrm{m}^{2} / \mathrm{g}\right)\end{array}$ & $\mathrm{S}_{\mathrm{I}} / \mathrm{S}_{\mathrm{BET}}$ & $\begin{array}{c}\mathrm{V}_{\mathrm{p}} \\
\left(\mathrm{cm}^{3} / \mathrm{g}\right)\end{array}$ & $\begin{array}{c}\mathrm{V}_{0.1} \\
\left(\mathrm{~cm}^{3} / \mathrm{g}\right)\end{array}$ & $\begin{array}{c}\mathrm{V}_{\text {meso }} \\
\left(\mathrm{cm}^{3} / \mathrm{g}\right)\end{array}$ & $\begin{array}{c}\mathrm{V}_{0.1} / \mathrm{V}_{\mathrm{p}} \\
(\%)\end{array}$ & $\begin{array}{c}\mathrm{R}_{\mathrm{p}} \\
\AA\end{array}$ \\
\hline CCS-1K700 & 594 & 564 & 680 & 0.83 & 0.202 & 0.179 & 0.023 & 88.6 & 11.8 \\
CCS-1K750 & 663 & 630 & 817 & 0.77 & 0.304 & 0.198 & 0.106 & 72.5 & 14.9 \\
CCS-1K800 & 743 & 706 & 950 & 0.74 & 0.423 & 0.275 & 0.121 & 65 & 17.8 \\
CCS-4K800 & 426 & 405 & 551 & 0.73 & 0.123 & 0.021 & 0.102 & 17.1 & 8.9 \\
\hline
\end{tabular}

Table 3. FTIR Absorption Bands for CS, CS-1K800 and CS-4K800 Samples

\begin{tabular}{cc}
\hline $\begin{array}{c}\text { Absorption bands } \\
\mathrm{cm}^{-1}\end{array}$ & Assignments \\
\hline $3600-3780$ & Free $\mathrm{O}-\mathrm{H}$ \\
$3100-3420$ & Hydrogen bonded $\mathrm{O}-\mathrm{H}$, adsorbed $\mathrm{H}_{2} \mathrm{O}$ \\
2950,2880 & Symmetric and asymm str of $-\mathrm{CH}_{3}-$ \\
1737 & $\mathrm{O}=\mathrm{C}-\mathrm{O}$ str \\
1627 & $\mathrm{C}=\mathrm{O}$ str \\
$1590-1595$ & $\mathrm{C}=\mathrm{C}$ str \\
$1420-1426$ & $-\mathrm{CH}_{2}-$ bending \\
$1324-1376$ & $\mathrm{C}-\mathrm{O}$ str in cyclic ether attached to double bonds or C-O asymmetric str in ether bridge group (pyronose ring) \\
1250 & C-O str in alcohols, $\mathrm{C}-\mathrm{O}-\mathrm{C}$ symmetric str \\
$1035-1050$ & Cut-of-plane bending of $\mathrm{C}-\mathrm{H}$ in aromatic structure \\
$600-900$ &
\end{tabular}

Nova Automated $\mathrm{N}_{2}$ gas adsorption at $77 \mathrm{~K}$. In addition, an estimate for micropore volume $\left(\mathrm{V}_{0.1}\right)$ was taken as volume of liquid nitrogen held at $\mathrm{P} / \mathrm{P}^{\circ}=0.1$ [33] in order to calculate mesopore volume from $\mathrm{V}_{\text {meso }}=\mathrm{V}_{\mathrm{p}}-\mathrm{V}_{0.1}$ (Table 2).

A scanning electron microscope, SEM-JEOL (JXA-840A Electron Probe Micro-Analyzer, Japan), was used to study the structural features of the cotton stalk raw material and activated sample (CCS-1K800). Before scanning, the selected samples were coated with gold (Au) using a quick autocoater (JFC-1500, JEOL). The surface functional groups were qualitatively determined by FTIR spectra of cotton stalks raw as well as for two selected carbons CCS-1K800 and CCS-4K800, recorded within the wavenumber range 4000 to $400 \mathrm{~cm}^{1}$. Analysis was achieved by a spectrophotometer Type FTIR-6100 (JASCO), employing the $\mathrm{KBr}$ pellets technique, was performed on those samples. Pressed $\mathrm{KBr}$ pellets at a sample $/ \mathrm{KBr}$ ratio of $0.2 \%(\mathrm{w} / \mathrm{w})$ were scanned after drying overnight at $100^{\circ} \mathrm{C}$. Functional group assignments by FTIR spectra on the selected carbon products are cited at Table 3.

\subsection{Adsorption procedures}

Iodine and methylene blue are considered as probe molecules for assessing the adsorption capacity of adsorbents for solutes of molecular sizes $>10$ and $>15 \AA$, respectively. Adsorption capacities of iodine and methylene blue are normally listed as specification parameters for commercial activated carbons.

\subsubsection{Iodine number estimation}

Iodine adsorption capacity (iodine number, $\mathrm{mg} / \mathrm{g}$ ) was determined by the titration of the residual solution of $10 \mathrm{ml}$ $\mathrm{I}_{2}$ with $0.1 \mathrm{~N}$ sodium thiosulphate in the presence of $1 \mathrm{ml}$ of $1 \mathrm{wt} \%$ starch solution as indicator. The iodine number was evaluated from the adsorbed iodine unit mass of the carbon adsorbent at the residual iodine concentration of $0.02 \mathrm{~N}$ [30].

2.3.2. Batch equilibrium experiments

For these experiments, a stock solution of methylene blue 
(MB), was prepared by dissolving $0.5 \mathrm{~g}$ in $1 \mathrm{~L}$ of distilled water in measuring flask of $1000 \mathrm{ml}$ capacity. $50 \mathrm{mg}$ of the powdered pre-dried carbon was mixed with $50 \mathrm{ml} \mathrm{MB}$ of increased concentrations $(50 \sim 300 \mathrm{mg} / \mathrm{l})$ in $250 \mathrm{ml}$ stopperedreagent bottles. The container bottles were agitated occasionally in a shaker for $72 \mathrm{~h}$ at ambient temperature to attain equilibrium. The residual dye concentration was determined using a UV-Vis spectrophotometer (Shimadzu Model PC2401) with $1.0 \mathrm{~cm}$ length-path cell. Absorbance measurements, of the properly diluted filtrates, were made at the maximum wavelengths of at $664 \mathrm{~nm}$. The amount of dye uptaken by the carbon samples was calculated by applying the massbalance equation;

$$
q_{e}=\frac{\left(C_{o}-C_{e}\right)}{m} V
$$

where $q_{e}$ is the amount of dye uptaken by the adsorbent (mg/ $\mathrm{g}), C_{o}$ initial dye concentration put in contact with the adsorbent $(\mathrm{mg} / \mathrm{l}), C_{e}$ equilibrium dye concentration $(\mathrm{mg} / \mathrm{l})$ after the batch adsorption procedure, $m$ mass of adsorbent in (mg) and $V$ the volume of dye put in contact with the adsorbent (ml).

\section{Results and Discussion}

\subsection{Effect of activation temperature on the carbon yield and ash content of prepared carbons}

The results of the activation yields and ash contents are given in Table 1. As expected, the carbon yields in the present case are extremely high and vary between 12 $24.5 \%$. The carbon yield generally decreases with raised temperature. A decrease in weight, and consequently in carbon yield, would be ascribed to enhanced gasification with raised temperature. On the other hand, the ash content appears to increase continuously with temperature from 700 to $800^{\circ} \mathrm{C}$ (from 2.81 up to $3.22 \%$ ). Thus, raising activation temperature is reflected on the ash content as a result of two factors : (a) relative increase in carbon gasification and (b) deposition of higher amounts of dehydrated / reacted potassium oxide or carbonate. Low ash contents in the produced carbons may be due to the effect of vigorous washing by $1 \mathrm{~N}$ $\mathrm{HCl}$ solution.

\subsection{Textural properties of the investigated carbons}

Fig. 1 shows a relationship between activation temperature $\left(700 \sim 800^{\circ} \mathrm{C}\right)$, with a ratio of $1: 1$, and BET-surface area and iodine coverage in $\mathrm{m}^{2} / \mathrm{g}$ (cf. Table 2). It can be observed that a big difference between surface area evaluated from nitrogen adsorption and iodine capacity, where $\boldsymbol{S}_{\boldsymbol{B E} \boldsymbol{T}}>\boldsymbol{S}_{\boldsymbol{I}}$ which owing to pore diameter size of $\mathrm{I}_{2}>\mathrm{N}_{2}$. This finding confirms that iodine, as established before, measures the

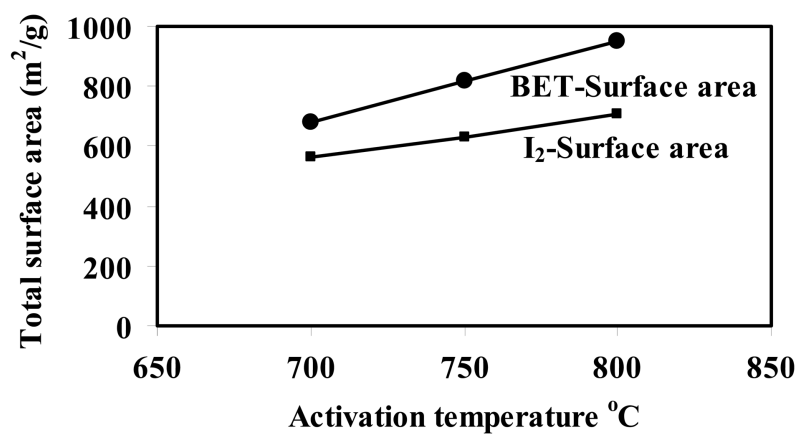

Fig. 1. Relationship between activation temperature (700 $800^{\circ} \mathrm{C}$ ), with a ratio of $1: 1$, and BET-surface area and iodine coverage in $\mathrm{m}^{2} / \mathrm{g}$.

surface area within pores at and beyond $10 \AA$ in diameter. From Table 2 , it can be seen that ratio of $\mathrm{S}_{\mathrm{I}} / \mathrm{S}_{\mathrm{BET}}$ decrease from 0.83 to 0.74 with developed porosity presented as $\mathrm{S}_{\mathrm{BET}}$ or $\mathrm{V}_{0.1}$ (Fig. 1).

It is well established that the activation temperature is one of the important parameters in the preparation of activated carbons using the chemical activation process [26]. In the present investigation, ratio of $\mathrm{KOH}$ to carbonized cotton stalks (CCS) was fixed at 1:1 in order to study the effect of activation temperature at 700,750 and $800^{\circ} \mathrm{C}$. Table 2 summarizes the textural parameters that were determined using $\mathrm{N}_{2}$ adsorption isotherms at $77 \mathrm{~K}$ (not shown here) according to the BET equation. It can be seen clearly that a considerable increase in the internal porosity of the developed carbons appears as the activation temperature increases from 700 to $800^{\circ} \mathrm{C} ; \mathrm{S}_{\mathrm{BET}}$ increases from 680 to $950 \mathrm{~m}^{2} / \mathrm{g} \quad(\sim 40 \%) ; \mathrm{V}_{\mathrm{p}}$ from 0.202 up to $0.423 \mathrm{~cm}^{3} / \mathrm{g}$ $(\sim 109 \%)$. This finding implies that the obtained semicarbonized cotton stalks- $\mathrm{KOH}$ activated possess a welldeveloped porosity, and could be prepared from $\mathrm{KOH}$ activation under the prescribed conditions. A significant increase in the average pore diameter was observed with increasing in activation temperature as follows: 11.8, 14.9 and $17.8 \AA$ for CCS-1K700, CCS-1K750 and CCS-1K800, respectively. This observation could be attributed to the formation of wide micropores (i.e., super-micropores $>7.2 \AA$ according to IUPAC classification) as activation temperature increases. Also, it can be observed that microporosity decreased as activation temperature increased from 88.6 to $65 \%$, accompanied by increasing in mesoporosity from 11.4 to $35 \%$. This trend confirms that the micropores are widening to generate mesopores or macropores inside the carbon matrix. Therefore, it is clearly noted that there is widening of porosity with increasing the activation temperature as shown in the following order: CCS-1K800 > CCS-1K750 >CCS$1 \mathrm{~K} 700$, respectively.

As the chemical ratio becomes $4: 1$ at an activation temperature at $800^{\circ} \mathrm{C}$, i.e. $\mathrm{CCS}-4 \mathrm{~K} 800$, it is observed that a 

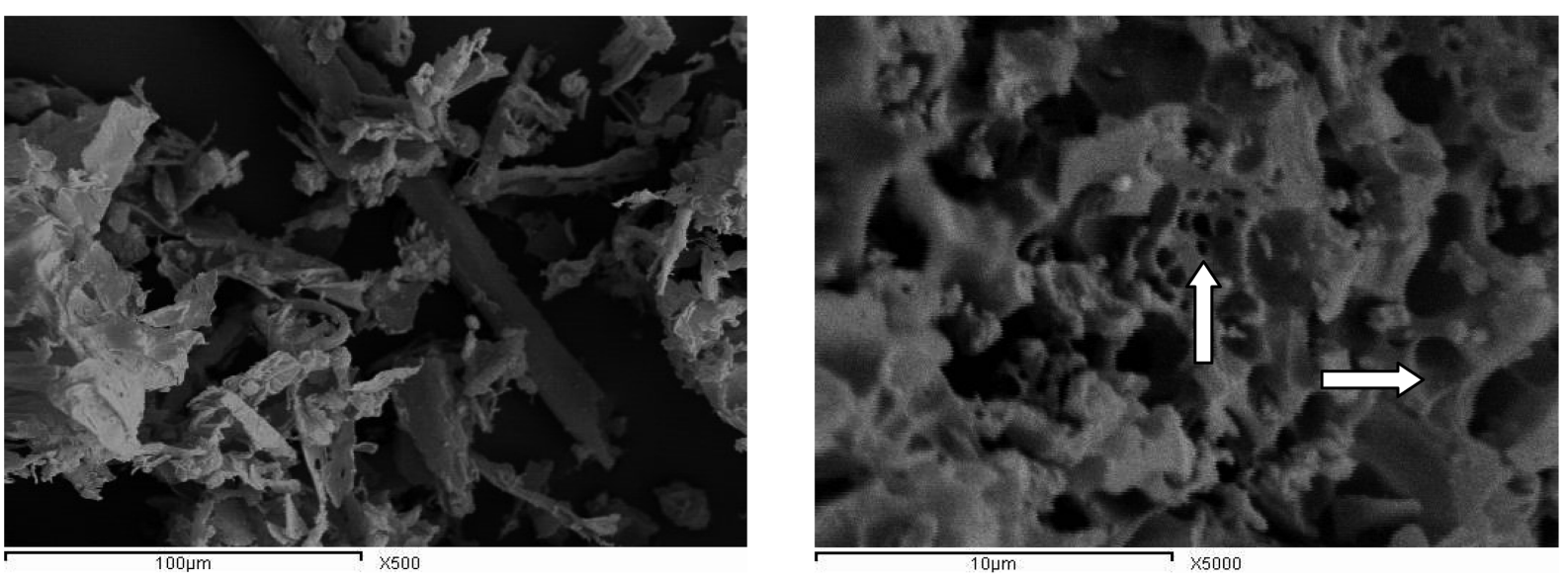

Fig. 2. SEM micrographs of cotton stalks (left) and CCS-1K800 (right).

considerable reduction appears in all textural parameters as listed in Table 2. This observation is not consistent with the previous studies on the activation of $\mathrm{KOH}$ with cotton stalks in one-stage, chemical ratios were $1: 1,2: 1$ and $3: 1$ at $700^{\circ} \mathrm{C}$ [12]; or other precursors, as e.g. spanish anthracite or corn cobs [34,35], where an increase in $\mathrm{KOH} /$ precursor (up to 4) resulted in enhanced porosity. Amongst the above literature, it was reported that $\mathrm{KOH}-$ a higher chemical ratio-works through two competing mechanisms of pore evolution in the carbon structure; (i) the formation of micropores which starts with the addition of $\mathrm{KOH}$ to the carbonaceous materials, and (ii) the gasification of surface carbon atoms through oxidation reaction at the carbonization temperature $700^{\circ} \mathrm{C}$. Both mechanisms lead to generation of an abundance of micropores [36].

Furthermore, It was established by Lozano-Castello et al. [34] that for the activated carbon carbonized at $700^{\circ} \mathrm{C}$, the highest porosity is obtained with a chemical ratio of 6 , whereas at $800^{\circ} \mathrm{C}$, the highest porosity occurs with $\sim 4.25$ of chemical ratio between $\mathrm{KOH}$ and precursor. Accordingly, this fact indicates that this may be ascribed to the nature of raw materials (i.e., physical and chemical properties) is important to produce the extent of porosity in corresponding to $\mathrm{KOH}$ activating agent. Hence, the lower carbonization temperature and lower chemical ratio $(\mathrm{KOH} / \mathrm{CCS}<4)$, are necessary in our case to obtain activated carbons with developed internal porosity. Also, a higher chemical ratio results in a collapse in internal porosity as observed in the tremendous drop in surface area, total pore volume and micropore volume (cf. Table 2). Thus it is not recommended with present precursor, i.e. cotton stalks, and that is much more sensitive to the action of $\mathrm{KOH}$ as it destructs its botanical structure with considerable gasification leading to a low carbon yield $\sim 12 \%$ (cf. Table 1). It can conclude that other previous precursors are more resistant to the action of $\mathrm{KOH}$ such as coal.

SEM microscopy is widely used to study the morphological features and surface characteristics of the carbonaceous adsorbents [37]. Fig. 2 depicts the SEM micrographs of parent cotton stalks and an activated sample, CCS-1K800 at two magnifications, 500x and 5000x, respectively. SEM micrograph of the original material illustrates its intact fibrous nature, where its activated carbon shows the formation of pores on the outer surface that can be further enhanced by chemical activation, which results in generation of large cavities (cf. arrows on SEM image of CCS-1K800). Thus destruction of the original defined fibers is accompanied by formation of a deformed mass with clear porosity, is indicated.

Fig. 3 shows the FTIR spectra for the original cotton stalks in comparison with the two activated carbonized cotton stalks; CCS-1K800 and CCS-4K800, in order to identify the oxygen functional groups on their surfaces and Table 3 illustrates the absorption bands for the studied samples. Absorption in the $3600-3780 \mathrm{~cm}^{-1}$ range, has been assigned to stretching of free $\mathrm{O}-\mathrm{H}$ groups on the surface [38]. In addition, hydrogen bonded $\mathrm{OH}$ groups can be assigned to broad peak in the $3350-3430 \mathrm{~cm}^{-1}$ range and a broad peak around $3300-3400 \mathrm{~cm}^{-1}$ is likely due to adsorbed water. A small intense peak in the range $2800-3000 \mathrm{~cm}^{-1}$ region is due to $\mathrm{C}-\mathrm{H}$ stretching modes. The band at 2980 and its shoulder at $2880 \mathrm{~cm}^{-1}$ were ascribed to $\mathrm{C}-\mathrm{H}$ symmetric and asymmetric stretching of residual methylene groups on the surface. It can be seen from the spectrum of cotton stalks in Fig. 3 that the peak intensities at $1737 \mathrm{~cm}^{-1}$ and $1250 \mathrm{~cm}^{-1}$ for ester and phenolic ether groups, respectively, disappeared considerably after $\mathrm{KOH}$ treatment. This observation confirms that the lignin which consists of many ester and ether bands in cross-linked structure is damaged by $\mathrm{KOH}$ impregnation [27]. Also, it is observed on the FTIR spectrum of cotton stalks that the peak at $1625 \mathrm{~cm}^{-1}$ is decreased in intensity and shifted to the lower wavenumber at $1600 \mathrm{~cm}^{-1}$ for CCS$1 \mathrm{~K} 800$. This peak has been attributed to $\mathrm{C}=\mathrm{O}$ stretching. 

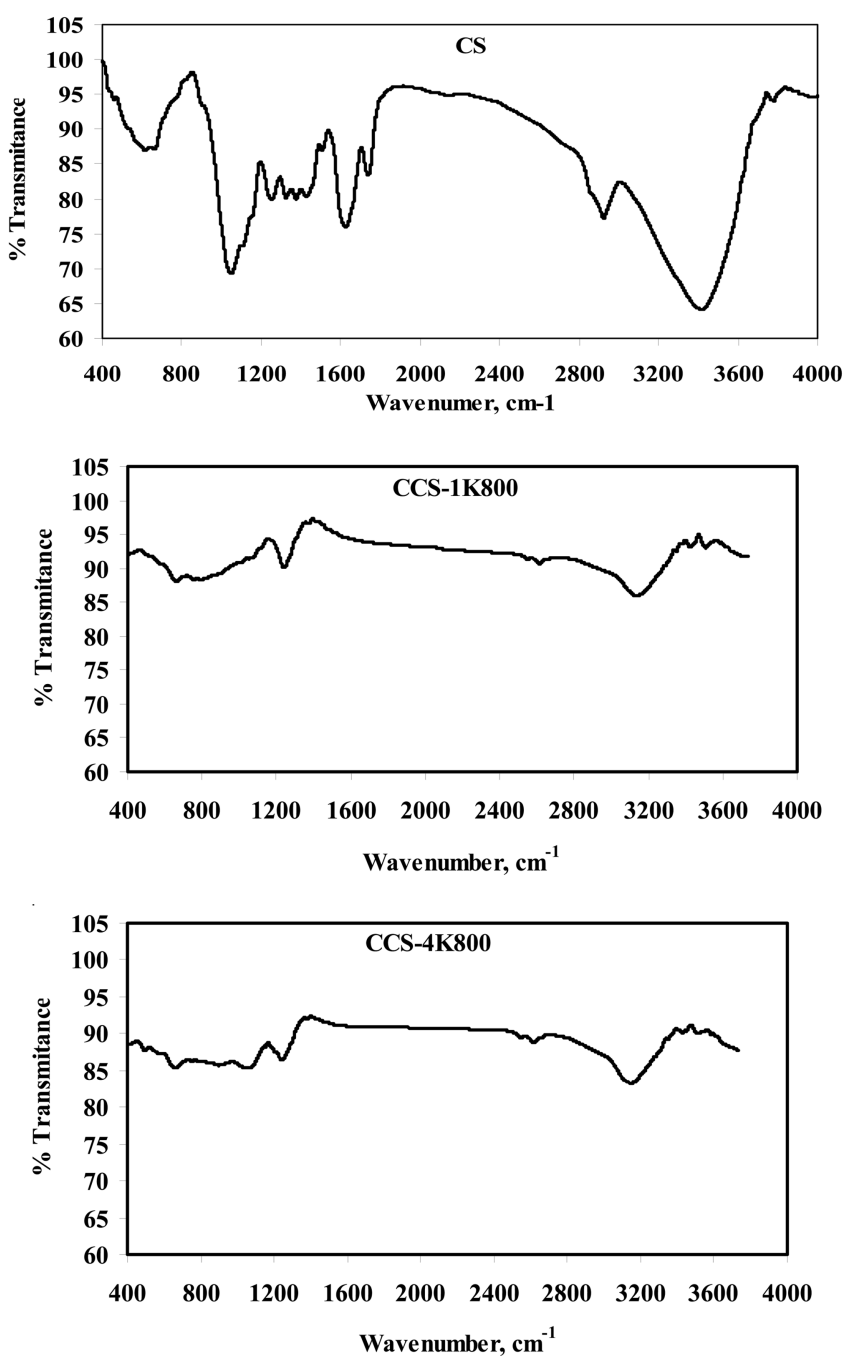

Fig. 3. FTIR spectra of the cotton stalks (CS), CCS-1K800 and CCS-4K800.

The peaks at $1620-1430 \mathrm{~cm}^{-1}$ region were ascribed to the skeletal $\mathrm{C}=\mathrm{C}$ stretching in aromatic rings. A band at $1373 \mathrm{~cm}^{-1}$ was ascribed to the formation of carboxyl-carbonate or carboxylic salt or metal carbonate. Bands between 1300 and $900 \mathrm{~cm}^{-1}$ which appear in all spectra have been currently assigned to $\mathrm{C}-\mathrm{O}$ stretching in acids, alcohols, phenols, ethers and esters [39]. Shoulder peaks appear between 900 and $600 \mathrm{~cm}^{-1}$ were assigned to an out-of-plane $\mathrm{C}-\mathrm{H}$ bending mode in aromatic rings. Overall, it can be concluded that FTIR analysis revealed the presence of $\mathrm{C}-\mathrm{O}, \mathrm{C}-\mathrm{O}-\mathrm{C}, \mathrm{O}=\mathrm{C}-$ $\mathrm{O}, \mathrm{C}-\mathrm{O}-\mathrm{H}, \mathrm{C}=\mathrm{O}-$ and some alkyl groups on the surface of studied samples. Chunlan et al. [29] studied the effect of precarbonization of petroleum cokes on chemical activation with $\mathrm{KOH}$. They found that the presented functional groups play a key role in the chemical activation process through two mechanisms as follows: (i) these surface functional

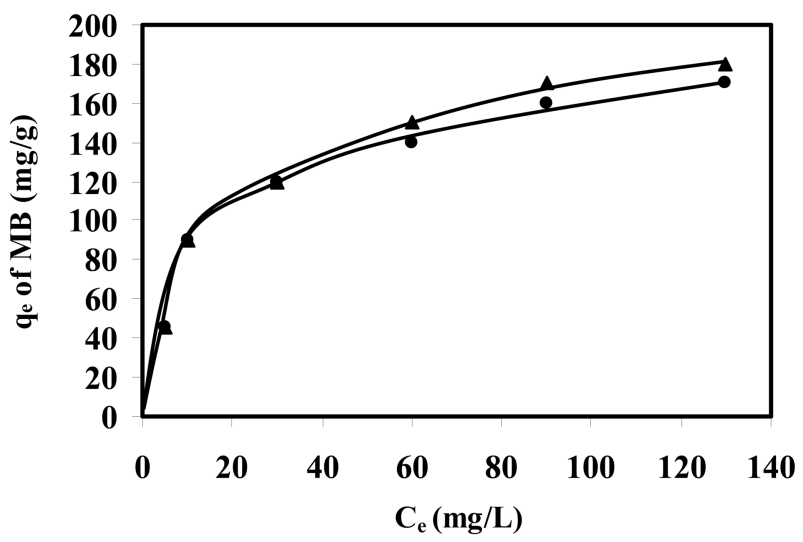

Fig. 4. Methylene blue adsorption isotherms on CCS-1K750 and CCS-1K800 ().

groups reacted with $\mathrm{KOH}$ and form the intermediate groups like $\mathrm{C}-\mathrm{O}-\mathrm{K}$; and then (ii) the resulted groups further reacted with the carbon of precursor to produce $\mathrm{K}_{2} \mathrm{CO}_{3}$ and $\mathrm{K}_{2} \mathrm{O}$ species, hence, porous structure is developed. Thus these surface functional groups can serve as "active sites" where chemical transformations occur via surface reactions [29] which enhance the adsorption capacity of these carbons towards hazardous materials.

\subsection{Adsorption isotherms for methylene blue (MB)}

Batch adsorption experiments were carried out on two activated samples CCS-1K750 and CCS-1K800, with welldeveloped porosity, for removal of methylene blue molecules from aqueous solution. The adsorption isotherms of various classes of compounds ( $q_{\mathrm{e}}$ versus $C_{\mathrm{e}}$ ) in different surfaces have been classified according to their shapes. In the literature, four types of isotherms have been reported [40], i.e., (i) the Langmuir type (L) with an initial concavity to the concentration axis, (ii) the S-type with an initial convexity to the concentration axis, (iii) the H-type resulting from extremely strong adsorption and having an intercept on the ordinate and (iv) the C-type having an initial linear portion. Adsorption isotherms expressing the adsorbed amounts as a function of equilibrium concentration for both wastewater samples are presented in Fig. 4. It is evident that the curves are all likely to be typical Langmuir-type adsorption isotherms.

Two isotherm equations are tested in this work, i.e. the Langmuir and Freundlich models. The applicability of the isotherm equations was compared by judging the correlation coefficients, $R^{2}$. The Langmuir isotherm equation has been widely applied to describe experimental adsorption data based on the assumption that maximum adsorption corresponds to a saturated monolayer of adsorbate molecules on adsorbate surface with a constant energy and there is no transmigration of adsorbate in the plane of adsorbate surface. The theoretical 

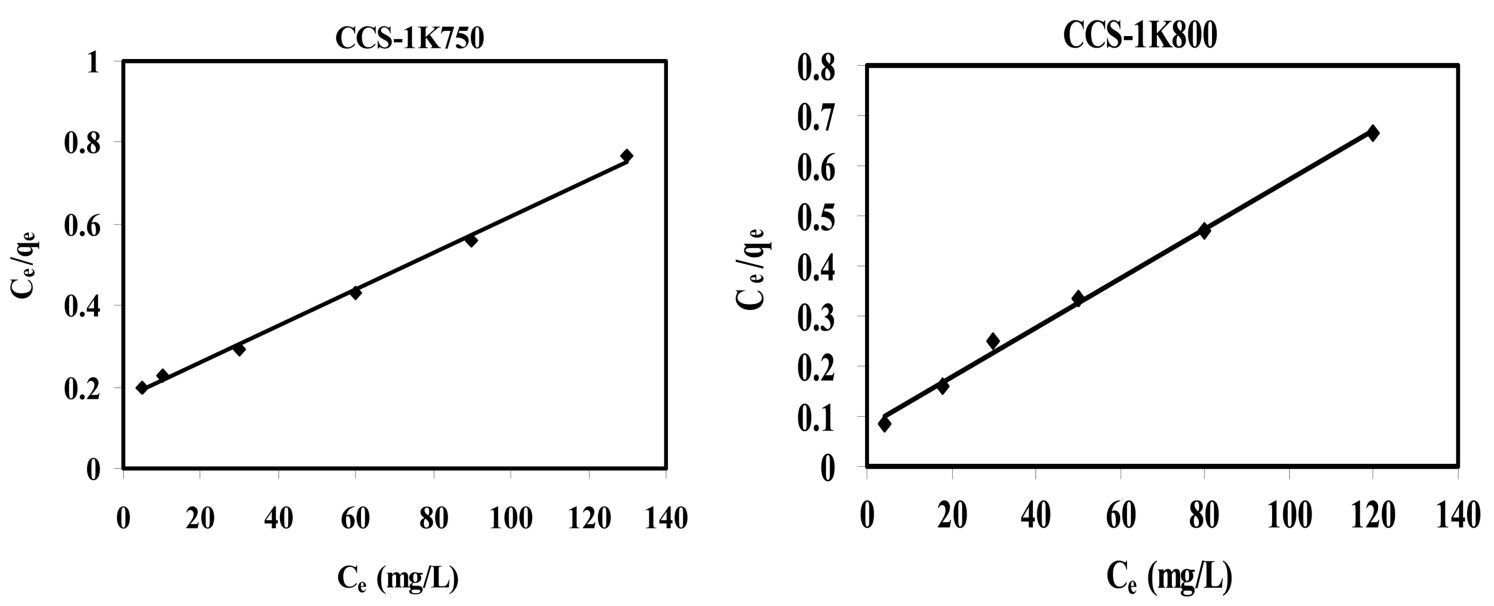

Fig. 5. Langmuir and Freundlich plots for methylene blue adsorption on CS-1K750.

Langmuir isotherm equation is represented by:

$$
q_{e}=\frac{q_{m o n} K_{L} C_{e}}{1+K_{L} C_{e}}
$$

where $K_{\mathrm{L}}$ is the Langmuir constant related to the energy of adsorption $(1 / \mathrm{mg})$ and $q_{\text {mon }}$ is the maximum amount of adsorption corresponding to complete monolayer coverage on the surface $(\mathrm{mg} / \mathrm{g})$. The constants $K_{\mathrm{L}}$ and $q_{\text {mon }}$ can be determined from the following linearized form of Eq. (2):

$$
\frac{1}{q_{e}}=\frac{1}{q_{\text {mon }}}+\frac{1}{q_{\text {mon }} K_{L}} \frac{1}{C_{e}}
$$

The linear plots of $1 / q_{\mathrm{e}}$ versus $1 / C_{\mathrm{e}}$ for the wastewater samples show that adsorption follows Langmuir isothermal model (Fig. 5). The $R^{2}$ values (0.996) suggest that the Langmuir isotherm provides a good fit to the isotherm data. Conformation of the experimental data into Langmuir isotherm model indicates the homogeneous nature of carbonized cotton stalks-KOH carbon surface, i.e., each dye molecule/CCS-KOH carbon adsorption has equal adsorption activation energy; the results also demonstrate the formation of monolayer coverage of dye molecule at the outer surface of sawdust carbon. A similar observation was reported for the adsorption of dyes onto activated carbon [41]. Values of $q_{\text {mon }}$ and $K_{\mathrm{L}}$ were evaluated from the intercept and slope of the linear plots, respectively, and are presented in Table 4. It can be seen that raising activation temperature improves the adsorption capacity from 198 to $222 \mathrm{mg} / \mathrm{g}(\sim 12.1 \%)$, which means an increase in accessible sites suitable for accommodation of the dye molecules (i.e. with dimensions $\geq 15 \AA$ ). By adopting the value of $120 \mathrm{~nm}^{2}$ for the molecular area of $\mathrm{MB}$ to estimate the area covered by adsorbate $\left(S_{M B}\right)$, then calculating the fractions covered by $\mathrm{MB}$ compared to the BET-surface areas as $\left(S_{M B} / S_{B E T}\right)$. It appears that the maximum fraction surface area covered by $\mathrm{MB}$ is $1 / 2$ of the total surface area which is accessible to MB molecules.

The essential features of Langmuir adsorption isotherm can be expressed in terms of a dimensionless constant called separation factor or equilibrium parameter $\left(R_{\mathrm{L}}\right)$, which is defined by the following relationship:

$$
R_{L}=\frac{1}{1+C_{o} K_{L}}
$$

where $C_{\mathrm{o}}$ is the initial dye concentration $(\mathrm{mg} / \mathrm{l})$. The $R_{\mathrm{L}}$ value indicates the shape of the isotherm to be irreversible $\left(R_{\mathrm{L}}=0\right)$, favorable $\left(0<R_{\mathrm{L}}<1\right)$, linear $\left(R_{\mathrm{L}}=1\right)$ or unfavorable isotherm $\left(R_{\mathrm{L}}>1\right)$. By processing the above equation, $R_{\mathrm{L}}$ values for investigated $\mathrm{MB}$ dye-adsorbent are found to be 0.007 for CCS-1K750 and 0.073 for CCS-1K800. From the values of $R_{\mathrm{L}}$, it is confirmed that prepared carbons are highly favorable for adsorption of basic dye from wastewater under the conditions used in this study.

The Freundlich isotherm is the earliest known relationship describing the sorption equation. This fairly satisfactory

Table 4. Langmuir and Freundlich Parameters for Methylene Blue (MB) Adsorption on CS-1K750 and CS-1K800 Samples $\left(\mathrm{C}_{0}=50-\right.$ 300, Equilibrium Time $=72 \mathrm{~h}$ )

\begin{tabular}{cccccccccc}
\hline & \multicolumn{4}{c}{ Langmuir parameters } & \multicolumn{3}{c}{ Freundlich parameter } \\
\hline $\begin{array}{c}\text { Sample } \\
\text { Notation }\end{array}$ & $\begin{array}{c}\mathrm{q}_{\text {mon }} \\
\mathrm{mg} / \mathrm{g}\end{array}$ & $\mathrm{K}_{\mathrm{L}}$ & $\mathrm{R}_{\mathrm{L}}$ & $\begin{array}{c}\mathrm{S}_{\mathrm{MB}} \\
\mathrm{m}^{2} / \mathrm{g}\end{array}$ & $\mathrm{S}_{\mathrm{MB}} / \mathrm{S}_{\mathrm{BET}}$ & $\mathrm{R}^{2}$ & $\mathrm{~K}_{\mathrm{F}}$ & $\mathrm{n}$ & $\mathrm{R}^{2}$ \\
\hline CS-1K750 & 198 & 0.435 & 0.007 & 448 & 0.548 & 0.996 & 34.1 & 3.30 & 0.905 \\
CS-1K800 & 222 & 0.042 & 0.073 & 502 & 0.528 & 0.996 & 31.4 & 2.77 & 0.866 \\
\hline
\end{tabular}



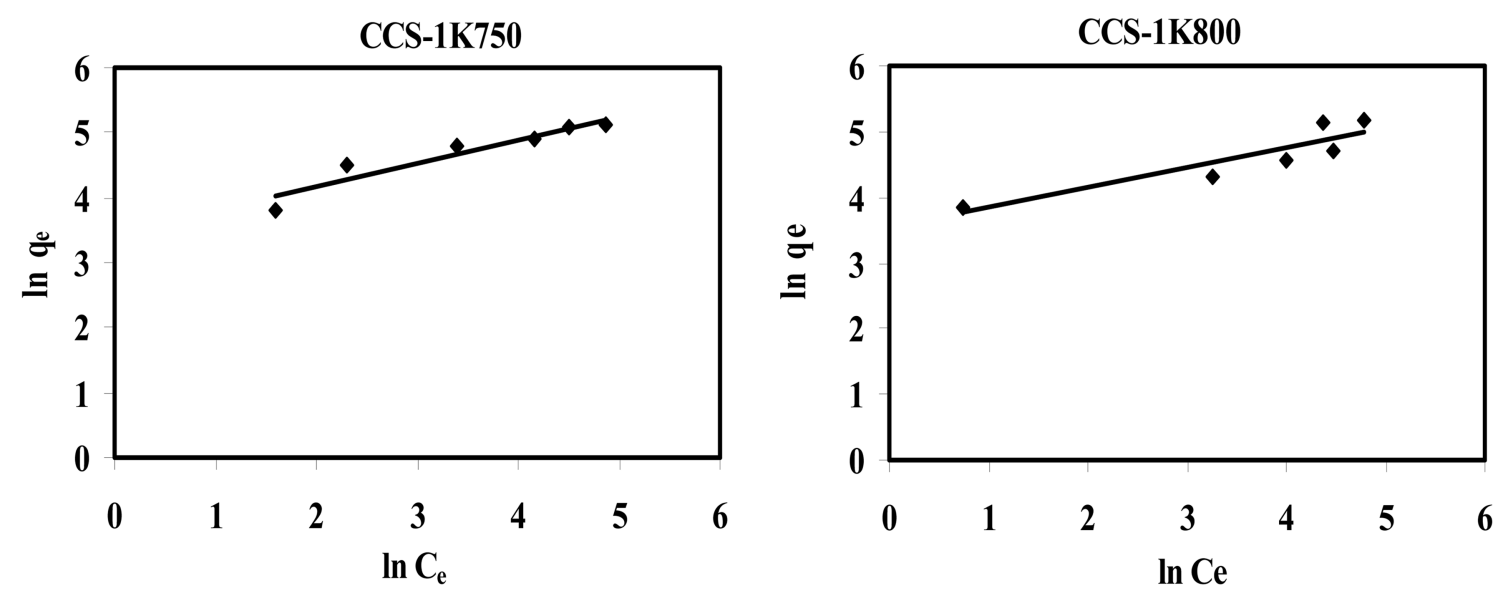

Fig. 6. Freundlich plots corresponding to adsorption of MB dye molecules.
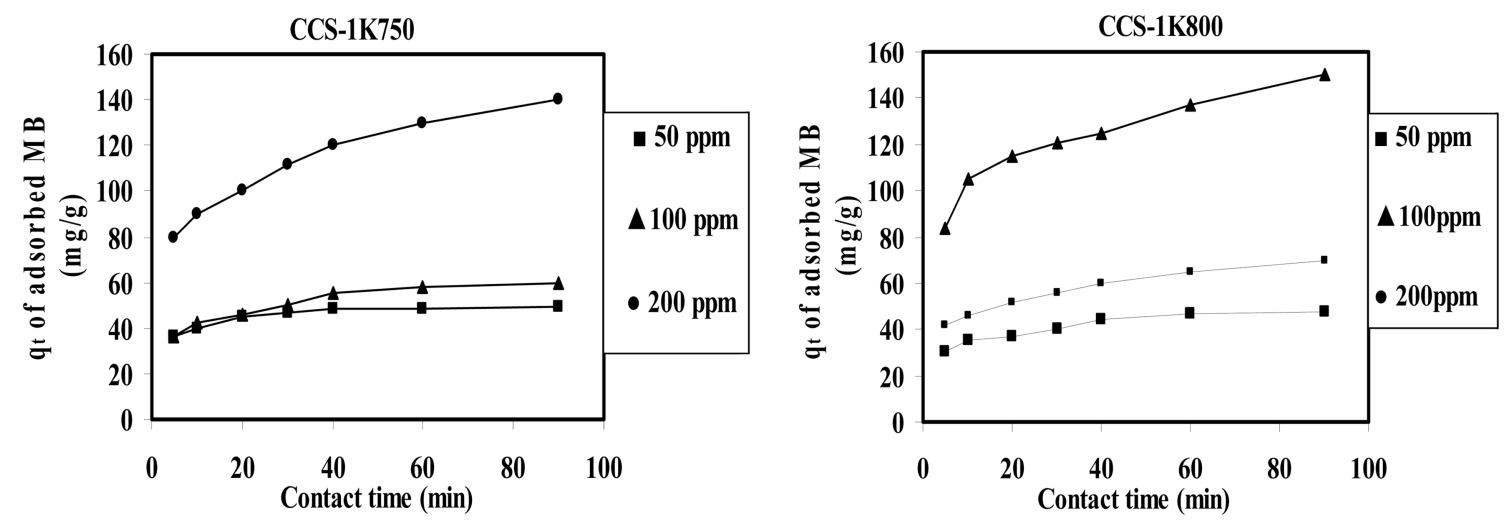

Fig. 7. Effect of initial concentration on the uptake of MB onto CCS-1K750 and CCS-1K800.

empirical isotherm can be used for non-ideal sorption that involves heterogeneous surface energy systems and is expressed by the following equation:

$$
q_{\mathrm{e}}=K_{\mathrm{F}} C_{\mathrm{e}}^{1 / n}
$$

where $K_{\mathrm{F}}\left(\mathrm{mg} / \mathrm{g}(\mathrm{L} / \mathrm{mg})^{1 / \mathrm{n}}\right)$ is roughly an indicator of the adsorption capacity and $1 / n$ is the adsorption intensity. In general, as the $K_{\mathrm{F}}$ value increases the adsorption capacity of adsorbent for a given adsorbate increases. The magnitude of the exponent, $1 / n$, gives an indication of the favorability of adsorption. Values of $n>1$ represent favorable adsorption condition. Equation (5) may be linearized by taking natural logarithmic (ln) values:

$$
\ln q_{\mathrm{e}}=\ln K_{\mathrm{F}}+\ln \ln C_{\mathrm{e}}
$$

Linear plots of $\ln q_{\mathrm{e}}$ versus $\ln C_{\mathrm{e}}$ show that adsorption of $\mathrm{MB}$ dye from wastewater on the CCS-1K800 also follow the Freundlich isotherm (Fig. 6), where $R^{2}$ equal to $0.866-0.905$. Values of $K_{\mathrm{F}}$ and $n$ are calculated from the intercepts and slopes of the plots, respectively, and found to be in range
31.4-34.1 and 2.77-3.30, respectively (cf. Table 4). The results suggest that $\mathrm{MB}$ dye molecules are favorably adsorbed by activated carbon prepared from cottons stalks. However, the values of the correlation coefficient $\left(R^{2}\right)$ (Table 4) indicate that the Langmuir isotherm better fitted for the adsorption of $\mathrm{MB}$ dye molecules on the obtained activated carbons.

\subsection{Adsorption kinetics of methylene blue under different conditions}

3.5.1. Effect of contact time and initial methylene blue concentration

The effect of the initial MB concentration on the MB adsorption by CCS-1K750 and CCS-1K800 is depicted in Fig. 7. It can be seen that the amount of dye adsorbed ( $q_{t}$, $\mathrm{mg} / \mathrm{g}$ ) increased with increased dye concentration in solution and remained constant after equilibrium time. The concentration provides an important deriving force to overcome all mass transfer resistance of the dye between the aqueous and 


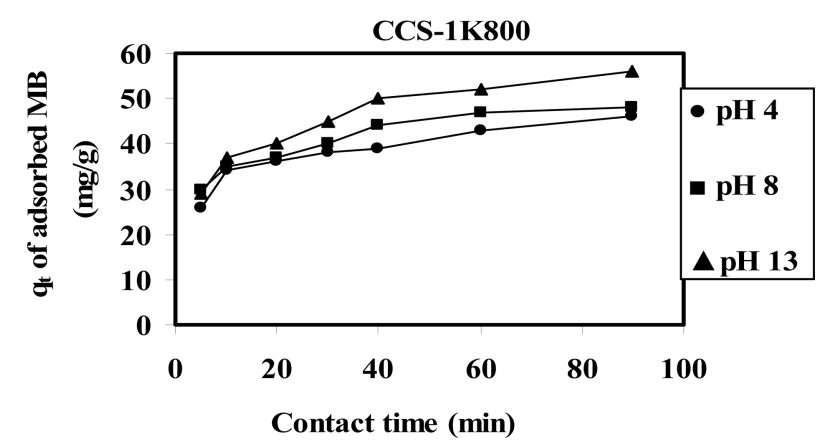

Fig. 8. Effect of solution $\mathrm{pH}$ on the uptake of $\mathrm{MB}$ of initial concentration $=50 \mathrm{mg} / \mathrm{L}$ onto $200 \mathrm{mg} \mathrm{CCS}-1 \mathrm{~K} 800$.

solid phases. Therefore, a higher initial concentration of MB dye will enhance the adsorption process. When the initial dye concentration increased from 50 to $200 \mathrm{ppm}(\mathrm{mg} / \mathrm{L})$, the amount uptake of MB onto CCS-1K750 increased from 49 to $140 \mathrm{mg} / \mathrm{g}$; and for CCS-1K800 from 48 onto $150 \mathrm{mg} / \mathrm{g}$, whereas the percentage removal decreased from 100 to $72 \%$ within $90 \mathrm{~min}$ (not shown here). Thus, the uptake of MB dye increased with increasing initial dye concentration, while the $\%$ removal of dye showed the opposite trend. A similar trend was also observed for MB dye adsorption onto bamboobased activated carbon [4,42].

Fig. 7 also indicate that the contact time needed for $\mathrm{MB}$ solutions with initial concentration $50 \sim 100 \mathrm{mg} / \mathrm{L}$ to reach equilibrium was less than $40 \mathrm{~min}$, whereas initial concentration of $200 \mathrm{mg} / \mathrm{L}$, equilibrium time of $60 \mathrm{~min}$ was attained.

3.5.2. Effect of solution $\mathrm{pH}$ on $\mathrm{MB}$ dye adsorption in relation to contact time

The effect of solution $\mathrm{pH}$ on the equilibrium uptake of $\mathrm{MB}$ by CCS- $1 \mathrm{~K} 800$ was studied at $50 \mathrm{mg} / \mathrm{L}$ initial dye concentration at $\mathrm{pH}=4,8$ and 13 as shown in Fig. 8. The dye uptake was found to increase with slightly increase from
46 to $56 \mathrm{mg} / \mathrm{g}$ for an increase in $\mathrm{pH}$ from 4 to 13 . Also, the required equilibrium time to reach maximum capacity through contact time plateau was $60 \mathrm{~min}$. Hence, as $\mathrm{pH}$ increased, the removal increased slightly. However, several investigations have reported that $\mathrm{MB}$ adsorption usually increases as the $\mathrm{pH}$ is increased $[43,44]$. This finding may be attributed to a decrease in accessible sites suitable for the accommodation of the MB molecules (i.e. with dimensions $\geq 15 \AA$ ). Principally, $\mathrm{MB}$ and other cationic dyes produce an intense molecular cation $\left(\mathrm{C}^{+}\right)$and reduced ions $\left(\mathrm{CH}^{+}\right)$. At high $\mathrm{pH}, \mathrm{OH}^{-}$on the surface of adsorbent will favor the adsorption cationic dye molecules. Otherwise, at low $\mathrm{pH}$ as 4 , the surface charge could be positively charged and $\mathrm{H}+$ ions are formed which competes effectively with dye cations leading to a decrease in the uptake of MB dye [4].

\subsubsection{Kinetic analysis}

Several kinetic models have been applied to examine the controlling mechanism of dyes adsorption from aqueous solutions and explain the obtained experimental data [9]. The kinetics of adsorption can be described by the first-order Lagergren equation that is given by Eq. (7):

$$
\log \left(q_{e}-q_{t}\right)=\log q_{e}-\frac{k_{1} t}{2.303}
$$

where $q_{e}$ and $q_{t}$ are the amounts of dye adsorbed at equilibrium $(\mathrm{mg} / \mathrm{g})$ and at time $t(\mathrm{~min})$ respectively, and $K_{l}$ is the equilibrium rate constant of pseudo first -order sorption $\left(\mathrm{min}^{-1}\right)$.

In some cases a pseudo-second-order model, given by Eq. $(8)$, in its linear form provides a better fit:

$$
t / q_{t}=1 /\left(K_{2} \cdot q_{e}^{2}\right)+t / q_{e}
$$

where $K_{2}$ is the equilibrium rate constant of pseudo second order adsorption ( $\mathrm{g} / \mathrm{mg} \mathrm{min}$ ), and $q_{e}$ in equation (7) can be obtained from the plot of $t / q_{t}$ vs. $t$; and there is no need to know any parameter beforehand. The calculated parameters

Table 5. Parameters of Kinetic Models from Methylene Blue Removal on $200 \mathrm{mg}$ CS-1K750 (Treated Volume of MB = $200 \mathrm{ml}$, Solution $\mathrm{pH}=8$ )

\begin{tabular}{cccccccc}
\hline \multirow{2}{*}{$\begin{array}{c}\text { Initial concentration } \\
\text { of MB }\end{array}$} & \multicolumn{3}{c}{ First order kinetic } & \multicolumn{3}{c}{ Second order kinetic } & \multicolumn{2}{c}{ Intraparticle diffusion } \\
\cline { 2 - 8 } & $\mathrm{q}_{\mathrm{e}}$ & $\mathrm{K}_{1}$ & $\mathrm{R}^{2}$ & $\mathrm{q}_{\mathrm{e}}$ & $\mathrm{K}_{2}$ & $\mathrm{R}^{2}$ & $\mathrm{k}_{\mathrm{p}}$ \\
\hline 50 & 19 & 0.025 & 0.979 & 48.9 & 0.01 & 0.999 & 2.8 \\
100 & 45 & 0.033 & 0.967 & 98 & $3.45 \times 10^{-4}$ & 0.988 & 6.3 \\
200 & 100 & 0.029 & 0.974 & 145.5 & $6.75 \times 10^{-4}$ & 0.982 & 7.7 \\
\hline
\end{tabular}

Table 6. Parameters of Kinetic Models from Methylene Blue Removal on $200 \mathrm{mg}$ CS-1K800 (Treated Volume of MB = $200 \mathrm{ml}$, Solution $\mathrm{pH}=8$ )

\begin{tabular}{cccccccc}
\hline $\begin{array}{c}\text { Initial concentration } \\
\text { of MB }\left(\mathrm{C}_{\mathrm{o}}\right)\end{array}$ & \multicolumn{3}{c}{ First order kinetic } & \multicolumn{3}{c}{ Second order kinetic } & \multicolumn{2}{c}{ Intraparticle diffusion } \\
\cline { 2 - 7 } & $\mathrm{q}_{\mathrm{e}}$ & $\mathrm{K}_{1}$ & $\mathrm{R}^{2}$ & $\mathrm{q}_{\mathrm{e}}$ & $\mathrm{K}_{2}$ & $\mathrm{R}^{2}$ & $\mathrm{k}_{\mathrm{p}}$ \\
\hline 50 & 30 & 0.033 & 0.965 & 51.5 & $3.78 \times 10^{-3}$ & 0.999 & 4.2 \\
100 & 58 & 0.063 & 0.967 & 110 & $4.45 \times 10^{-4}$ & 0.988 & 4.9 \\
200 & 100 & 0.024 & 0.966 & 190 & $1.22 \times 10^{-3}$ & 0.982 & 5.5 \\
\hline
\end{tabular}




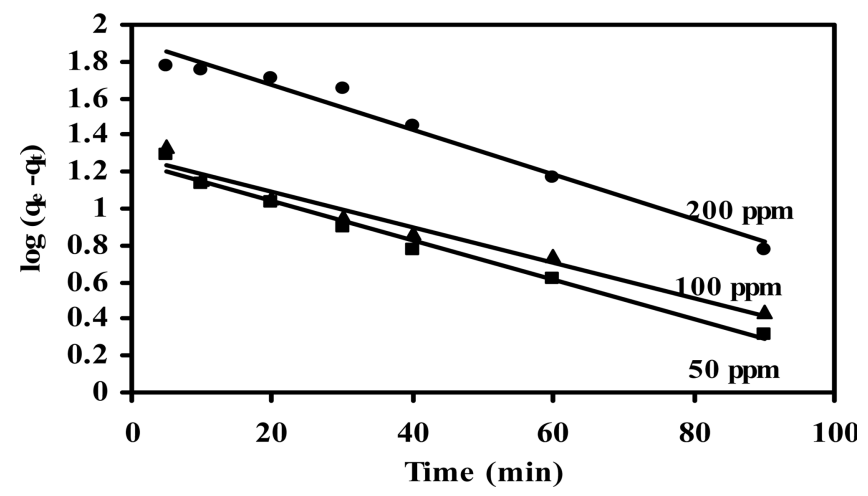

Fig. 9. Pseudo-first-order kinetics for the adsorption of $200 \mathrm{ml}$ MB dye onto $200 \mathrm{mg}$ of CCS-1K750.

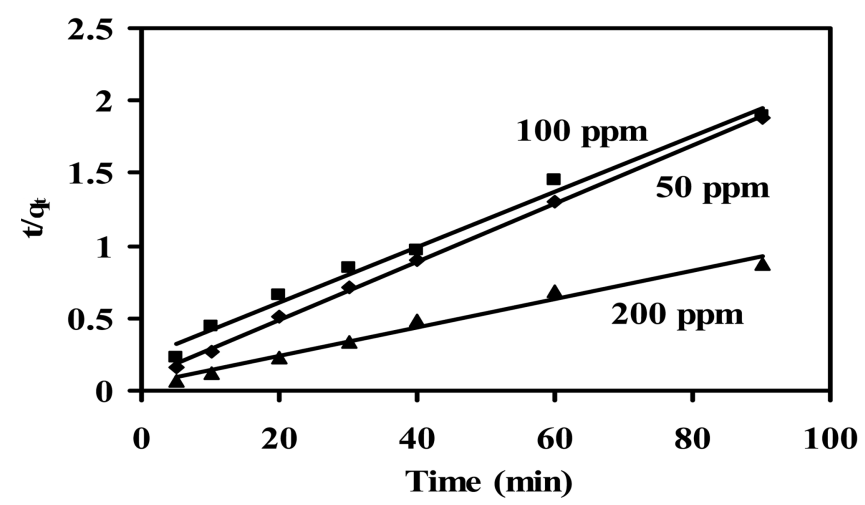

Fig. 10. Pseudo-second-order kinetics for the adsorption of $\mathrm{MB}$ dye onto $200 \mathrm{mg}$ of CCS-1K750.

of two kinetic models are cited in Table 5 and 6 for CCs$1 \mathrm{~K} 750$ and CCS-1K800 (initial concentration $=50 \sim 200 \mathrm{mg} / \mathrm{L}$, treated volume of $\mathrm{MB}=200 \mathrm{ml}$, adsorbent weight $=200 \mathrm{mg}$, $\mathrm{pH}=8$ at $25^{\circ} \mathrm{C}$ ). The plots of pseudo- first-, and-second-order for the adsorption of MB dye on CCS-1K750 are shown in Figs. 9 and 10, respectively.

From Table 5 and 6 , it can be seen that the correlation coefficient $\left(R^{2}\right)$ for the Lagergren equation are slightly lower than for those obtained from pseudo-second-order $(0.982-$ 0.999 ) as well as the calculated $q_{e}$ values by this equation are closer or reasonable to the experimental ones. This confirms a very good agreement with the experimental, thus, the adsorption kinetic could well be approximated more favorably by the pseudo-second-order kinetic model for the entire sorption period. It was reported that in many cases the pseudo-first-order equation does not fit well to the whole range of contact time and is generally applicable over the initial stage of the adsorption process [41]. Therefore, the pseudo-second-order kinetic model was used further to study the adsorption of methylene blue onto activated carbons [41].

The kinetic adsorption results were further analyzed by the

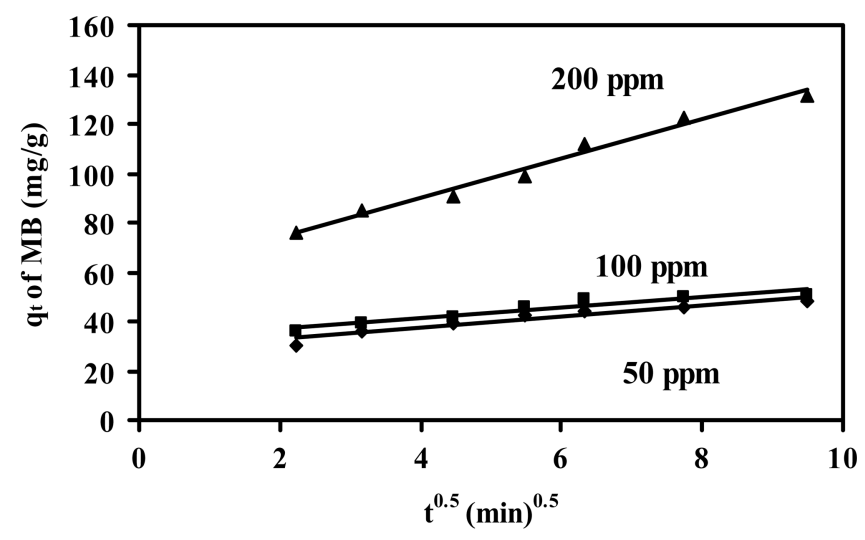

Fig. 11. Intra-particle diffusion plot for the adsorption of $M B$ onto CCS-1K750.

intra-particle diffusion model to elucidate the diffusion mechanism [45], and given by the expression:

$$
\mathrm{q}_{\mathrm{t}}=K_{P} \mathrm{t}^{0.5}
$$

where, $K_{P}$, the rate constant for intraparticle diffusion $(\mathrm{mg} / \mathrm{g}$ $\min ^{0.5}$ )is calculated from the slope of linear portion of $q_{t}-$ $t^{0.5}$ plot in Fig. 11 and listed in Table 5 and 6 . The linear plots are attributed to the pore diffusion that is accessible sites of adsorption. This is ascribed to the instantaneous utilization of the most readily available adsorbing sites on the adsorbent surface. It can be seen from Fig. 11, the $q_{t}-$ $t^{0.5}$ plot are linear over the whole time range, implying that one process affected the adsorption, i.e. boundary layer diffusion (pore diffusion) of solute molecules. Also, values of intercept give an idea about the thickness of boundary layer, i.e., larger the intercept with greater the boundary layer effect [9]. Usually, three consecutive steps involved in the adsorption of dye molecules by a porous adsorbent, to identify the rate determining step controlling the removal rate in adsorption process, are: (i) transport of the adsorbate (dye molecule) to the external surface of the adsorbent (film diffusion); (ii) transport of the adsorbate within the pores of adsorbent (pore diffusion); (iii) adsorption of the adsorbent on the external surface of adsorbent. In general, the process (iii) is very rapid and does not represent the rate-determining step in the uptake of adsorbate molecules. In our case, the removal kinetic of methylene blue dye on the obtained carbons follows pore diffusion process.

\section{Conclusion}

Activated carbons derived from pre-semi-carbonization followed by $\mathrm{KOH}$ activation of cotton stalks, with different activation temperatures and chemical ratios of $\mathrm{KOH}$, proved to be good-quality carbon adsorbents. Increased activation temperature enhanced surface area and pore volume up to 
$950 \mathrm{~m}^{2} / \mathrm{g}$ and to $0.423 \mathrm{~cm}^{3} / \mathrm{g}$, respectively. Good adsorption capacity for methylene blue (MB) appears, under equilibrium conditions, attaining values of $222 \mathrm{mg} / \mathrm{g}$ associated with the texture properties (surface area and pore volume). Langmuir isotherm model adequately fits to the adsorption data. Within kinetic experiments, the pseudo-second-order model better explained the adsorption kinetics as compared to the pseudofirst-order model. The results of this study indicate that such laboratory carbons derived from cotton stalks could be employed as low cost alternative to commercial carbons in wastewater treatment.

\section{References}

[1] Attia, A. A.; Girgis, B. S.; Fathy, N. A. Dyes and Pigments 2008, 76, 282.

[2] O'Neil, C.; Hawkes, F. R.; Hawkes, D. L.; Lourenco, N. D.; Pinheiro, H. M.; Delee, W. J. Chem. Technol. 1999, 74, 1009.

[3] Singh, K. P.; Malik, A.; Sinha, S.; Ojha, P. J. Hazard. Mater. 2008, 150, 626.

[4] Kavitha, D.; Namasivayam, C. Biores. Technol. 2007, 98, 14.

[5] Goyal, M.; Singh, S.; Bansal, R. C. Carbon Sci. 2004, 5, 170.

[6] Malik, P. K. Dyes and Pigments 2003, 56, 239.

[7] Pereira, M. F. R.; Soares, S. F.; Orfao, J. J. M.; Figueiredo, J. L. Carbon 2003, 41, 811.

[8] Teng, R. L.; Wu, F. C.; Juang, R. S. Carbon 2003, 41, 487.

[9] Kannan, N.; Sundaran, M. M. Dyes and Pigments 2001, 51, 25.

[10] El-Haaggar, S. M.; Younis, A.; Dwidar, M.; Nabet, M.; Hoseny, S. "Utilization of agricultural wastes and sewage for the development of the Egyptian agricultural community", B. Sc. Project, Mechanical Engineering Department, American University, Egypt, 2001.

[11] Girgis, B. S.; Ishak, M. F. Mater. Letters 1999, 39, 107.

[12] El-Hendawy, A. A.; Alexander, A. J.; Andrews, R. J.; Forrest, G. J. Anal. Appl. Pyrolysis 2008, 82, 272.

[13] Girgis, B. S.; Smith, E.; Louis, M. M.; El-Hendawy, A. A. J. Anal. Appl. Pyrolysis 2009, 86, 180.

[14] Bansal, R. C.; Donnet, J. B.; Stoeckli, F. “Active Carbon", Marcel Dekker, New York, 1988, Chap. 1.

[15] Bansal, R. C.; Goyal, M. "Activated Carbon Adsorption”, Taylor and Francis, CRC Press, Boca Raton, New York, 2005.

[16] Girgis, B. S.; Attia, A. A.; Fathy, N. A. Coll. Surf. A Physicochem. Eng. Aspects 2007, 299, 79.

[17] Khalil, L. B.; Girgis, B. S.; Tawfik, T. A. M. Adsorpt. Sci. Technol. 2000, 18, 373.
[18] Stavropoulos, G. G.; Zabaniotou, A. A. Micropor. Mesopor. Mater. 2005, 82, 79.

[19] Philip, C. A., Girgis, B. S. J. Chem. Technol. Biotechnol. 1996, 67, 248

[20] Ahmedna, M.; Marshall, W. E.; Rao, R. M. Bioresource Technol. 2000, 71,113.

[21] Banat, F.; Al-Asheh, S.; Makhadmeh, L. Adsorp. Sci. Technol. 2003, 21, 597.

[22] Aygun, A.; Yenisoy-Karakas, S.; Duman, I. Micropor. Mesopor. Mater. 2003, 66, 189.

[23] Aggarwal, P.; Dollimore, D. Thermal Anal. 1997, 50, 523.

[24] Tseng, R.-L.; Tseng, S.-K. J. Coll. Interf. Sci. 2005, 287, 428.

[25] El-Hendawy, A. A. Appl. Surf. Sci. 2009, 255, 3723.

[26] Park, S.-J.; Jung, W.-Y. Carbon Sci. 2001, 2, 10.

[27] Oh, G. H.; Yun, C. H.; Park, C. R. Carbon Sci. 2003, 4, 180.

[28] Lillo-Rodanes, M. A.; Cazorla-Amoros, D.; Linares-Solano, A. Carbon 2003, 41, 267.

[29] Chunlan, L.; Shaoping, X.; Yixiong, G.; Shuqin, L.; Changhou, L. Carbon 2005, 43, 2295.

[30] Oh, G. H.; Park, C. R. Fuel 2002, 81, 327.

[31] Giles, C. H.; da'Silva, A. P.; Trivedi A. S. Proceedings of the international symposium on surface area determination, 1969, 317.

[32] Srinivasakannan, C.; Abu Bakar, M. Z. Biomass and Bioenergy 2004, 27, 89.

[33] Gomez-Serrano, V.; Cuerda-Correa, E. M.; FernandezGonzalez, M. C.; Alexandre-Franco, M. F.; Macias-Garcia, A. Mater. Letters 2005, 59, 846.

[34] Lozano-Castello, D.; Lillo-Rodanes, M. A.; CazorlaAmoros, D.; Linares-Solano, A. Carbon 2001, 39, 741.

[35] Ahmadroup, A.; Do, D. D. Carbon 1997, 35, 1723.

[36] Nelly, J. W.; Isacoff, E. G. "Carbonaceous adsorbents for the treatment of ground and surface water", Marcel Dekker, New York, 1982.

[37] Park, S. H.; McClain, S.; Tian, Z. R.; Suib, S. L.; Karwacki, C. Chem. Mater. 1997, 9, 176.

[38] Puziy, A. M.; Poddubnaya, O. I.; Martínez-Alonso, A.; Suárez-García, F.; Tascón, J. M. D. Carbon 2002, 40, 1493.

[39] Moreno-Castilla, C. Carbon 2004, 42, 83.

[40] Ho, Y. S.; McKay, G. Trans IChem E 1998, 76, 332.

[41] Hameed, B. H.; Din, A. T. M.; Ahmed, A. L. J. Hazard. Materials 2007, 141, 819.

[42] Gupta, V. K.; Suhas, A. I.; Saini, V. K. Ind. Eng. Chem. Res. 2004, 43, 1740.

[43] Singh, K. P.; Mohan, D.; Sinha, S.; Tondon, G. S.; Gosh, D. Ind. Eng. Chem. Res. 2003, 42, 1965.

[44] Weber, T. W; Chakravorti, R. K. J. A. IChem E 1974, 20, 228. 